Frederick A. Burrows MD FRCPC, ${ }^{* \dagger}$ Robert H. Taylor mb FFARCS, * Simon C. Hillier MB FFarCs*

\title{
Early extubation of the trachea after repair of secundum-type atrial septal defects in children
}

To investigate the role of anaesthetic management in early extubation of the trachea in children after closure of a secundum-type atrial septal defect (ASD II), a retrospective chart review for a two-year period was performed. We identified 36 children who underwent surgical repair of an isolated ASD II. In 19 children $(53 \%)$ the tracheas were extubated in the operating room immediately after surgery and in 17 patients (47\%) the tracheas remained intubated and the lungs were ventilated in the Intensive Care Unit. There was no difference in age $(69.5 \pm 33.8$ vs $72.9 \pm 45.0 \mathrm{mo})$ or weight $(19.5 \pm 8.1$ versus $20.5 \pm 12.7 \mathrm{~kg})$ between the two groups (mean \pm SD). Children in the extubated group had a shorter duration of cardiopulmonary bypass (43.4 $\pm 7.8 \mathrm{~min})$ than those remaining intubated $(31.7 \pm 12.7 \mathrm{~min})(P$ $<0.05)$. The children whose tracheas were extubated early received a lower perioperative fentanyl dose $(5.9 \pm 6.4$ $\mu \mathrm{g} \cdot \mathrm{kg}^{-1}$ ) than those remaining intubated (35.J $\pm 8.5 \mu \mathrm{g} \cdot \mathrm{kg}^{-1}$ ). Those children in the extubated group had a lower hourly requirement for morphine by infusion $(13.6 \pm 5.7$ vs $18.2 \pm 5.4$ $\left.\mu \mathrm{g} \cdot \mathrm{kg}^{-1} \cdot \mathrm{hr}^{-1}\right)$ and a shorter stay $(20.5 \pm 3.7$ versus $29.0 \pm$ $11.2 \mathrm{hr}$ ) in the Intensive Care Unit. Re-intubation of the trachea was not required in any of the children and no deaths occurred. Early extubation after ASD II repair is safe and, given the results of this study, may offer certain advantages over prolonged intubation and ventilation in these children.

\section{Key words}

HEART: congenital defects, atrial septal defect; INTUBATION: tracheal.

From the Departments of Anaesthesia* and Paediatrics (Cardiology) $\dagger$ and the Research Institute, The Hospital for Sick Children and University of Toronto, Toronto, Ontario, Canada. Address correspondence to: Dr. Frederick A. Borrows, Department of Anaesthesia, The Hospital for Sick Children, 555 University Avenue, Toronto, Ontario, Canada M5G 1 X8. Accepted for publication 23rd August, 1992.
Pour une période de deux années, nous avons révisé rétrospectivement nos dossiers de fermeture chirurgicale de communication interauriculaire de type ostium secundum (CIA II) dans le but d'étudier l'influence de la conduite de l'anesthésie sur l'extubation postopératoire précoce. Nous avons identifís 36 enfants ayant subi une chirurgie correctrice d'une CIA II isolee. Dans 19 cas (53\%), la trachée fut extubée en salle d'opération immédiatement après la chirurgie, alors que dans $17(47 \%)$, on a maintenu la trachée intubée et la ventilation contrôlée à l' unité de soins intensifs. Il n'y avait pas de différence d'âge $(69 \pm 33,8$ vs $72 \pm 45,0$ mois $)$ ou de poids $(19,5 \pm 8,1$ vs $20,5 \pm 12,7 \mathrm{~kg})$ entre les groupes (moyenne \pm ET). Pour les enfants du groupe extubé la durée de la CEC $(23,4 \pm 7,5 \mathrm{~min})$ avait été moindre que pour ceux du groupe intubé $(31.7 \pm 12,7 \mathrm{~min})(P<0,05)$. Les enfants extubés précocement ont reçu une dose de fentanyl periopératoire infériure $\left(5,9 \pm 6,4 \mu \mathrm{g} \cdot \mathrm{kg}^{-1}\right)$ à ceux qu'on a gardés intubess $\left(35,1 \pm 8,5 \mu \mathrm{g} \cdot \mathrm{kg}^{-1}\right)$. En postopératoire, pour le groupe des extubés précoces la dose horaire de morphine en perfusion a été moins élevée $(13,6 \pm 5,7$ vs $18,2 \pm 5,4$ $\left.\mu \mathrm{g} \cdot \mathrm{kg}^{-1} \cdot \mathrm{hr}^{-1}\right)$ et le séjour moins prolongé $(20,5 \pm 3,7 \mathrm{vs} 29,0$ $\pm 11,2 \mathrm{hr})$ d l'unité de soins intensifs. La réintubation endotrachéale ne fut jamais nécessaire dans aucun des graupes et aucun décès n'est survenu. L'extubation précoce apres la correction chirurgicale d'une CIA II ne présente donc pas de danger particulier, si on considère les résultats de la présente étude, et peut même présenter certains avantages sur l'intubation et la ventilation prolongées.

The postoperative management of children who have undergone cardiac surgery with cardiopulmonary bypass (CPB) differs among institutions. Certain studies ${ }^{1-5}$ suggest that early extubation of the trachea in selected patients is not associated with increased morbidity or mortality. It has also been demonstrated that lung compliance in children immediately after anaesthesia for repair of secundum-type atrial septal defect (ASD II) is the same as that after anaesthesia for non-cardiothoracic surgery. ${ }^{6}$ However, there are marked cardiorespiratory changes after $\mathrm{CPB}$, including ventilation/perfusion inequalities and 
prolonged sedative and respiratory depressant effect of narcotics. ${ }^{7,8}$ Although mechanical ventilation after CPB decreases the work of breathing, prolonged intubation of the trachea in children has been associated with tube displacement, blockage, and increased susceptibility to infection. ${ }^{9,10}$ To investigate the suitability of early extubation after ASD II repair in children, we reviewed our experience over a two-year period.

\section{Methods}

With the approval of the Human Ethics Committee of The Hospital for Sick Children, Toronto, Ontario, we performed a retrospective chart review of all patients who had undergone surgical closure of an ASD II during the twoyear period 1988 to 1990 .

From a computer search of hospital records that used the single diagnosis of ASD II repair as the criterion, a total of 36 patients were identified. From the review of their charts, their age and body weight at the time of surgery were recorded, as was the duration of cardiopulmonary bypass (CPB) and aortic cross-clamp (XCL). The anaesthetic technique, including the dose and type of narcotic analgesic drug, was recorded from the anaesthetic chart. Time of admission to the Intensive Care Unit (ICU), time to extubation, and time to discharge from the ICU were recorded, along with the dose of morphine infusion used during the patient's stay. The $\mathrm{pH}$ and arterial carbon dioxide tension $\left(\mathrm{PaCO}_{2}\right)$ were recorded from the first arterial blood gas analysis performed in the ICU; these were taken as a measure of the adequacy of ventilation. Untoward complications or mortality recorded on the chart were also noted.

The children were divided into two groups according to whether their tracheas were extubated immediately after surgery (extubated group) or taken to the ICU where their tracheas remained intubated and their lungs mechanically ventilated (intubated group).

An unpaired Student's $t$ test was used for analysis of the differences between the two groups of children; $P<0.05$ was accepted as an indication of statistical significance.

\section{Results}

All children reviewed were classified as ASA physical status 2 on the basis of their congenital cardiac lesion; they suffered no other medical problems.

None of the children received sedative premedication. Patient monitoring was established before induction with a sphygmometer, Doppler flow probe, electrocardiograph, oxygen saturation monitor, and precordial stethoscope. All children received thiopentone from one of several different anaesthetists. Neuromuscular blockade was achieved with pancuronium $0.15 \mathrm{mg} \cdot \mathrm{kg}^{-1}$ iv. Nasotracheal intubation was performed and intermittent positive pressure ventilation was commenced with an air/oxygen mixture $\left(\mathrm{FIO}_{2}\right.$ of
0.3-1.0). Anaesthesia was maintained with isoflurane and fentanyl $i$. Supplemental doses of fentanyl and pancuronium were administered as necessary. After the completion of induction of anaesthesia, an arterial catheter was inserted for measurement of systemic arterial pressure and intermittent blood sampling. The precordial stethoscope was replaced with an oesophageal stethoscope and rectal, oesophageal and peripheral skin temperature monitoring was established.

After anticoagulation with heparin $300 \mathrm{IU} \cdot \mathrm{kg}^{-1}$, nonpulsatile CPB was established with a standard roller pump (Cobe Canada Ltd., Scarborough, Ontario) and a Capiox ${ }^{(8)}$ hollow fibre membrane oxygenator (Terumo, Tokyo, Japan). The CPB circuit was primed with packed red blood cells, $5 \%$ albumin and plasmalyte (Travenol, Mississauga, Ontario) solution plus mannitol $1 \mathrm{~g} \cdot \mathrm{kg}^{-1}$ to maintain a haematocrit of $25-30 \%$ during CPB. Normal CPB flows were calculated as $2.4-3.2 \mathrm{~L} \cdot \mathrm{m}^{-2} \cdot \mathrm{min}^{-1}$. In 19 patients the aorta was cross-clamped and cardioplegia was administered. Cardioplegia consisted of $300 \mathrm{ml} \cdot \mathrm{m}^{-2}$ body surface area of modified Roe's solution to which 20 $\mathrm{mEq} \cdot \mathrm{L}^{-1}$ of sodium bicarbonate solution was added. Patients were cooled to a minimum rectal temperature of $30.4 \pm 2.1^{\circ} \mathrm{C}$. Alpha-stat acid base management was used. The $\mathrm{PaCO}_{2}$ was maintained between $32-37 \mathrm{mmHg}$ and $\mathrm{pH}$ between 7.35-7.40. Arterial blood gas determinations were performed with a Nova Stat Profile 5 blood gas analyzer (Nova Biomedical, Waltham, Massachusetts).

At the end of the procedure the patients were rewarmed to $36^{\circ} \mathrm{C}$ rectally and weaned from CPB. The heparin effect was reversed with protamine, titrated until the activated clotting time was within ten seconds of the baseline value. In those children whose tracheas were extubated in the operating room, the neuromuscular blockade was reversed with atropine $\left(20 \mu \mathrm{g} \cdot \mathrm{kg}^{-1}\right)$ and neostigmine $\left(50 \mu \mathrm{g} \cdot \mathrm{kg}^{-1}\right)$. Adequacy of reversal was assessed by a train-of-four ratio of greater than 0.7 and the presence of a normal respiratory pattern and vital capacity (subjectively assessed). Reintubation was not required in any patient; none died. The tracheas of 19 children (53\%) were extubated immediately after surgery; $17(47 \%)$ remained intubated and the lungs were ventilated in the ICU. The children in the extubated group received supplemental humidified oxygen by open-face mask and experienced no hypoxaemia $\left(\mathrm{PaO}_{2}<80 \mathrm{mmHg}\right)$.

There were no differences in age $(69.5 \pm 33.8$ vs 72.9 $\pm 45.0 \mathrm{mth})$ or body weight $(19.5 \pm 8.1$ vs $20.5 \pm 12.7$ $\mathrm{kg}$ ) between the two groups (mean $\pm \mathrm{SD}$ ) (Table I). The children in the extubated group underwent a shorter duration of CPB $(23.4 \pm 7.8 \mathrm{~min})$ than those in the intubated group $(31.7 \pm 12.7 \mathrm{~min})(P<0.05)$. However, the duration of aortic cross-clamp was not different between the two groups (Table I). The aorta was crossclamped and cardioplegia was administered to eight 
TABLE I Patient characteristics and comparison of length of procedures

\begin{tabular}{llllll}
\hline & \multicolumn{2}{l}{ Patients } & & \multicolumn{2}{l}{ Length of procedure } \\
\cline { 2 - 5 } $\begin{array}{llll}\text { Group } \\
(n=36)\end{array}$ & Age $(\mathrm{mo})$ & Weight $(\mathrm{kg})$ & & CPB $(\mathrm{min})$ & XCT $(\mathrm{min})$ \\
\hline Extubated $(n=19)$ & $69.5 \pm 33.8$ & $19.5 \pm 8.1$ & & $23.4 \pm 7.8 *$ & $13.3 \pm 6.3 \dagger$ \\
Intubated $(n=17)$ & $72.9 \pm 45.0$ & $20.5 \pm 12.7$ & & $31.7 \pm 12.7$ & $15.3 \pm 6.8 \ddagger$ \\
\hline
\end{tabular}

Cardiopulmonary bypass (CPB), aoric cross-clamp (XCT).

$* P<0.05$. $\$ 8$ children. $¥ 11$ children, Mean \pm SD.

Table II Comparison of blood gas data and fentanyl dosage

\begin{tabular}{llll}
\hline & \multicolumn{3}{l}{ Blood gas data } \\
\cline { 2 - 4 } $\begin{array}{l}\text { Group } \\
\text { (n=36) }\end{array}$ & $p H$ & $\begin{array}{l}P a C O \\
(m m H g)\end{array}$ & $\begin{array}{l}\text { Fentanyl } \\
\left(\mu g \cdot \mathrm{kg}^{-1}\right)\end{array}$ \\
\hline Extubated $(n=19)$ & $7.33 \pm 0.04 \dagger$ & $44.9 \pm 5.1 \dagger$ & $5.9 \pm 6.4^{*}$ \\
Intubated $(n=17)$ & $7.51 \pm 0.08$ & $29.7 \pm 6.5$ & $35.1 \pm 8.5$ \\
\hline
\end{tabular}

$* P<0.05 . \dagger P<0.001$. Mean $\pm \mathrm{SD}$.

Table III Comparison of amount morphine infused and length of stay in the ICU

\begin{tabular}{lcl}
\hline $\begin{array}{l}\text { Group } \\
(n=36)\end{array}$ & $\begin{array}{l}\text { Morphine infusion } \\
\left(\mu g \cdot \mathrm{kg}^{-1} \cdot \mathrm{hr}^{-1}\right)\end{array}$ & $\begin{array}{l}\text { Length of stay in the ICU } \\
(\mathrm{hr})\end{array}$ \\
\hline Extubated $(n=19)$ & $3.6 \pm 5.7^{*}$ & $20.5 \pm 3.7 \dagger$ \\
Intubated $(n=17)$ & $18.2 \pm 5.4$ & $29.0 \pm 11.2$ \\
\hline
\end{tabular}

$+P<0.05 .+P<0.01$. Intensive Care Unit (ICU). Mean $\pm \mathrm{SD}$.

children in the extubated group and to 11 in the intubated group.

The dose of fentanyl used differed greatly between the two groups. The extubated group received a lower total dose $\left(5.9 \pm 6.4 \mu \mathrm{g} \cdot \mathrm{kg}^{-1}\right)$ than the intubated group (35.1 $\pm 8.5 \mu \mathrm{g} \cdot \mathrm{kg}^{-1}$ ) (Table II).

No difficulty in maintaining clinically acceptable haemodynamic function after the children were weaned from CPB was identified in either group of patients, nor was there evidence of a change in technique from one designed for early extubation of the trachea to one designed for more prolonged intubation. Similarly, there was no haemodynamic instability nor need to restore normal temperature homeostasis that precluded immediate postoperative extubation of the trachea in any of the $\mathbf{3 6}$ children reviewed.

To summarize the anaesthetic management, our retrospective chart review suggested that the decision whether to extubate the trachea of a child after repair of the ASD II was made before induction. We could not identify any patient factors precluding early extubation of the trachea in any of the 36 children reviewed. Although not statistically significant, several anaesthetists had a greater proportion of patients in the extubated group than others.

Analysis of the first arterial blood gas in the ICU demonstrated a lower arterial pH $(7.33 \pm 0.04)$ and higher
$\mathrm{PaCO}_{2}(44.9 \pm 5.1 \mathrm{mmHg})$ for the children in the extubated group than with the values $(7.51 \pm 0.08$ and $29.7 \pm 6.5 \mathrm{mmHg}$ respectively; $P<0.01$ ) for those comprising the intubated group (Table II).

Postoperative analgesia in the ICU consisted of morphine administered by infusion with the technique for closing and assessment, as previously described. ${ }^{11}$ The extubated group had a lower hourly requirement for morphine by infusion $\left(13.6 \pm 5.7 \mu \mathrm{g} \cdot \mathrm{kg}^{-1} \cdot \mathrm{hr}^{-1}\right.$ ) and were discharged earlier from the ICU $(20.5 \pm 3.7 \mathrm{hr})$ than the intubated group $\left(18.2 \pm 5.4 \mu \mathrm{g} \cdot \mathrm{kg}^{-1} \cdot \mathrm{hr}^{-1}\right.$ and $29.0 \pm$ $11.2 \mathrm{hr}$ respectively) (Table III).

Re-intubation of the trachea was not required in any of the children and no deaths occurred.

\section{Discussion}

This study demonstrates that, with appropriate intraoperative management, safe and successful extubation of the trachea can be performed in children after repair of ASD II before they leave the operating theatre. Such early extubation expedites patient flow through the ICU and frees up resources for other patients.

Repair of ASD II in children requires a relatively short duration of CPB, which may attenuate postoperative cardiorespiratory problems. Barash et al. ${ }^{5}$ suggested that periods of CPB longer than $30 \mathrm{~min}$ were associated with 
prolonged postoperative intubation of the trachea. We found an average duration of CPB of $24 \mathrm{~min}$ in the extubated group and $32 \mathrm{~min}$ in the group remaining intubated and ventilated. Although these times were different $(P<0.05)$, we do not believe that the difference in the duration of CPB between the two groups is a clinically important factor in the prolonged intubation in these children.

The differences in technique, such as the enthusiasm of the cardiovascular team for early extubation, may introduce a large bias in the dosage of narcotic analgesic and may account for the difference seen in this study, since different anaesthetists were involved. Previous studies have suggested that the anaesthetic technique is an important factor in the determination of the suitability of a patient for early extubation. Barash et al. ${ }^{5}$ have suggested that the use of inhalational anaesthesia facilitates early extubation. Although the cardiovascular status of our patients was such that a pure inhalational technique could have been used, intraoperative fentanyl was administered in all cases, although the total dosages were less for the patients who were extubated in comparison with those for the group who remained intubated (Table II). Similarly, Schuller $e t$ al ${ }^{4}$ found that, in more critically ill patients, administering small doses of fentanyl $\left(10 \mu \mathrm{g} \cdot \mathrm{kg}^{-1}\right)$ reduced the need for an inhalational agent, provided greater cardiac stability, and did not complicate extubation of the trachea at the end of the procedure.

Our finding that postoperative respiratory depression was not related to either early or late extubation of the trachea compares with that of other studies in children. ${ }^{3-5}$ Although patients in the extubated group had a lower mean arterial $\mathrm{pH}$ and a higher mean $\mathrm{PaCO}_{2}$ than those remaining intubated and ventilated, the values were not clinically significant, and neither respiratory support nor reintubation was required in any of the study patients.

The intubated group received, on average, higher hourly doses of morphine by infusion in the ICU and remained longer before being discharged from the ICU (difference of nine hours). This result suggests that the intubated group required increased sedation, which may, in itself, have necessitated a prolonged stay in the ICU. Furthermore, the ICU staff may have been reluctant to perform tracheal extubation earlier than $12 \mathrm{hr}$ after CPB because they may have preferred to maintain mechanical ventilation overnight to allow the spontaneous reversal of the neuromuscular blockade. A time saving of nine hours in a patient's stay in the ICU represents a potentially important contribution to ICU resources, especially if it is time saved during that period of the day when there are elective admissions to the ICU.

Extubation of the trachea immediately after ASD II repair still requires that the children be carefully monitored and that facilities for cardiorespiratory support, including intubation of the trachea, be available. Our findings, taken with those of previously published studies, indicate that early extubation in selected children after cardiac surgery does not appear to cause any increase in mortality or morbidity and may represent considerable resource savings.

\section{Acknowledgement}

This paper was prepared with the assistance of Medical Publications, The Hospital for Sick Children, Toronto, Ontario.

\section{References}

1 Joachimsson P-O, Nystrom S-O, Tyden M. Early extubation after coronary artery surgery in efficiently rewarmed patients: a postoperative comparison of opioid anesthesia versus inhalational anesthesia and thoracic epidural analgesia. J Cardiothorac Anesth 1989; 3: 444-54.

2 Hinds $\mathrm{CJ}$. Current management of patients after cardiopulmonary bypass. Anaesthesia 1982; 37: 170-91.

3 Manners $J M$, Monro JL, Edwards JC. Corrective cardiac surgery in infants. A review of 136 patients including the contribution of postoperative ventilation. Anaesthesia 1980: 35: 1149-56.

4 Schuller JL, Bovill JG, Nijveld A, Patrick MR, Marcelletti $C$. Early extubation of the trachea after open heart surgery for congenital heart disease. A review of 3 years' experience. Br J Anaesth 1984; 56: 1101-8.

5 Barash PG, Lescovich F, Katz JD, Talner NS, Stansel $H C J r$. Early extubation following pediatric cardiothoracic operation: a viable altemative. Ann Thorac Surg 1980; 29: 228-33.

6 Shulman DL, Burrows FA, Poppe DJ. Smallhorn JS. Perioperative respiratory compliance in children undergoing repair of atrial septal defects. Can J Anaesth 1991; 38: 292-7.

7 McClenahan JB, Young WE, Sykes MK. Respiratory changes after open-heart surgery. Thorax 1965;20: 545-54.

8 Rea HH, Harris EA, Seelye ER, Whitlock RML, Withy SJ. The effects of cardiopulmonary bypass upon pulmonary gas exchange. J Thorac Cardiovase Surg 1978; 75 ; $104-20$.

9 Thung N, Herzog P. Christlieb II, Thompson WM Jr, Dammann JF Jr. The cost of respiratory effort in postoperative cardiac patients. Circulation 1963; 28: 552-9.

10 Markham WG, Blackwood MJA, Conn AW. Prolonged nasotracheal intubation in infants and children. Can Anaesth Soc J 1967; 14: 11-21.

11 Lynn AM, Opheim KE, Tyler DC. Morphine infusion after pediatric cardiac surgery. Crit Care Med 1984; 12: 863-6. 